\title{
Brocchi, Darwin, and Transmutation: Phylogenetics and Paleontology at the Dawn of Evolutionary Biology
}

\author{
Stefano Dominici • Niles Eldredge
}

Published online: 30 September 2010

(C) Springer Science+Business Media, LLC 2010

\begin{abstract}
Giambattista Brocchi's (1814) monograph (see Dominici, Evo Edu Outreach, this issue, 2010) on the Tertiary fossils of the Subappenines in Italy-and their relation to the living molluscan fauna-contains a theoretical, transmutational perspective ("Brocchian transmutation”). Unlike Lamarck (1809), Brocchi saw species as discrete and fundamentally stable entities. Explicitly analogizing the births and deaths of species with those of individual organisms ("Brocchi's analogy"), Brocchi proposed that species have inherent longevities, eventually dying of old age unless driven to extinction by external forces. As for individuals, births and deaths of species are understood to have natural causes; sequences of births and deaths of species produce genealogical lineages of descent, and faunas become increasingly modernized through time. Brocchi calculated that over $50 \%$ of his fossil species are still alive in the modern fauna. Brocchi's work was reviewed by Horner (1816) in Edinburgh. Brocchi's influence as a transmutational thinker is clear in Jameson's (1827) "geological illustrations" in his fifth edition of his translation of Cuvier's Theory of the Earth (read by his student Charles Darwin) and in the anonymous essays of 1826 and 1827 published in the Edinburgh New Philosophical Journal — which also carried a notice of Brocchi's
\end{abstract}

S. Dominici $(\bowtie)$

Museo di Storia Naturale, Sezione di Geologia e Paleontologia,

Università di Firenze,

via La Pira 4,

50121 Florence, Italy

e-mail: stefano.dominici@unifi.it

N. Eldredge

Division of Paleontology,

The American Museum of Natural History,

Central Park West@ $@$ 79th St,

New York, NY 10024, USA death in 1827 . The notion that new species replace older, extinct ones - in what today would be called an explicitly phylogenetic context-permeates these essays. Herschel's (1830) discussion of temporal replacement of species and the modernization of faunas closely mirrors these prior discussions. His book, dedicated to the search for natural causes of natural phenomena, was read by Charles Darwin while a student at Cambridge. Darwin's work on HMS Beagle was in large measure an exploration of replacement patterns of "allied forms" of endemic species in time and in space. His earliest discussions of transmutation, in his essay February 1835, as well as the Red Notebook and the early pages of Notebook B (the latter two written in 1837 back in England), contain Brocchi's analogy, including the idea of inherent species longevities. Darwin's first theory of the origin of species was explicitly saltational, invoking geographic isolation as the main cause of the abrupt appearance of new species. We conclude that Darwin was testing the predicted patterns of both Brocchian and Lamarckian transmutation as early as 1832 at the outset of his work on the Beagle.

Keywords Giambattista Brocchi · John Herschel · Charles Darwin · Transmutation

It was widely accepted among savants [i.e. in the $1830 \mathrm{~s}]$, even in Britain, that some kind of natural process, as yet unknown, must be responsible for the origin of new species (M. Rudwick 2008).

In this Special Issue of Evolution: Education and Outreach devoted to the topic of phylogenetics, we explore the early history of transmutational thinking, emphasizing the expansion of systematics from its foundational role in 
the recognition (and consequent classification) of natural groups of "allied forms," into a full blown search for patterns of genealogical descent-a pursuit initially confined to studies of the fossil record and in particular to the scientific explanation of the origin of the modern fauna (see also Eldredge 2010, this issue). This paper augments the historical background that led to Darwin's initial work on transmutation while serving as unpaid ship's naturalist while on the HMS Beagle from 1831 to 1836 as initially (and in greater detail) described by Eldredge (2009a). A companion paper (Dominici 2010, this issue) provides for the first time an English translation of the key components of Brocchian transmutation as originally published in Brocchi (1814).

Jean-Baptiste Lamarck stands as the premier icon of preDarwinian transmutationism. Debates in Great Britain (and elsewhere) in the 1820 s and 1830 s over "transmutation" generally centered around Lamarck's ideas (and to a lesser extent those of his younger colleague Etienne Geoffroy St. Hilaire). Those adamantly opposed to transmutation, like William Whewell for example, generally focused on attacking Lamarck (Whewell 1837). And Lyell's (1832) second volume of his Principles of Geology (see Secord 1991), while quietly leaving the door open for some explanation of the origin of species in natural causal terms eventually to be discovered a century or two down the road, was primarily a no-holds-barred attack on Lamarck's ideas.

In like manner, those who favored transmutation tended to agree explicitly with Lamarck - the best example lying with the "Edinburgh Lamarckians" (Secord 1991), such as Darwin's mentor Robert Grant, the geologist Robert Jameson (who may have penned the pro-Lamarckian anonymous essay of 1826 printed in his own journal [Anonymous 1826]), and others. The standard storyline is that Darwin succeeded where Lamarck ultimately failed because, with natural selection, which Darwin discovered in 1838, Darwin had a plausible mechanism to explain evolution - one that has clearly stood the test of time.

Rather than comparing putative causal mechanisms for transmutation, we suggest that examining competing empirically based claims of natural biological pattern reveals not one but two forms of transmutational thinking in Great Britain in the 1820s and 1830s. Lamarck's central claim - a prediction, in effect-is that if transmutation is "true," we should ultimately expect to document constant change within species, such that a perfect data set of fossils would reveal complete intergradation between "species" through time; and we would as well expect to see similar patterns of smooth intergradation among living species geographically. Lamarck (1809) wrote "Let me repeat that the richer our collections grow, the more proofs do we find that everything is more or less merged into everything else, that noticeable differences disappear, and that nature usually leaves us nothing but minute, nay puerile, details on which to found our distinctions" (Elliot 1984). That claim was the very hallmark of Lamarck's transmutation.

Lyell, alluding to Lamarck, put the problem in the opening page of his second volume very well as he invited his reader to:

Inquire first, whether species have a real and permanent existence in nature; or whether they are capable, as some naturalists pretend, of being indefinitely modified in the course of a long series of generations (1832).

For Lamarck, species are spatiotemporally neither discrete nor stable. The counter claim-that species indeed are discrete and stable - is of course a foundational tenet of the religiously based view of creation, the very opposite of transmutation. As the creationist natural philosopher Whewell (the man who coined the term "science") put it, "Species have a real existence in nature and a transition from one to another does not exist" (Whewell 1837; Hull 1973; [in a later edition "transition" is changed to "transmutation"; Whewell 1858]).

But there was a third alternative - a form of transmutation that saw species as discrete and stable, yet connected through successions of births and deaths forming lineages of ancestry and descent of "allied forms"-all attributable to natural causes. Thus descendant species replace extinct ones through time. This line of thinking was fully naturalistic and scientific - a second, explicitly non-Lamarckian, form of transmutation that was originated by the Italian geologist and paleontologist Giambattista Brocchi-whose work was widely read, discussed and, in some quarters, admiredespecially in Edinburgh.

If it was Brocchi who pioneered this second, separate line of transmutational thinking, it was none other than Charles Robert Darwin who was its final champion while on HMS Beagle (1831-1836) and for a time, after he arrived back in England. While in South America, Darwin documented the replacement of an extinct by a modern congeneric species - and also compared allopatric distributions of what he always saw as discrete living species in southern South America, culminating in his recognition of levels of replacement patterns in the Galapagos avifauna. Tellingly, neither man was an admirer of Lamarck.

\section{Giambattista Brocchi}

Giambattista Brocchi was born in Bassano del Grappa in 1772, training as a historian and a mineralogist. In 1814, Brocchi published Conchiologia Fossile Subapennina, the second important monograph on Tertiary molluscan pale- 
ontology after Lamarck's (1802-1809) work on the invertebrate fossils of the Paris Basin, published between 1802 and 1806 (Rudwick 2005). Finding more living analogs in the modern seas (over $50 \%$, Brocchi claimed) along the Italian coast than Lamarck could point to with his (older) rocks and fossils, Brocchi used his data to speculate on the births and deaths of species (Fig. 1) (Brocchi 1814). Indeed, in two remarkable passages, he disparaged both the study of fossils with no living analogs [“...busying ourselves to plot a distinct genealogy of some obscure descent since long gone"; see the accompanying article (Dominici 2010, this issue) for translated excerpts of

\section{a}
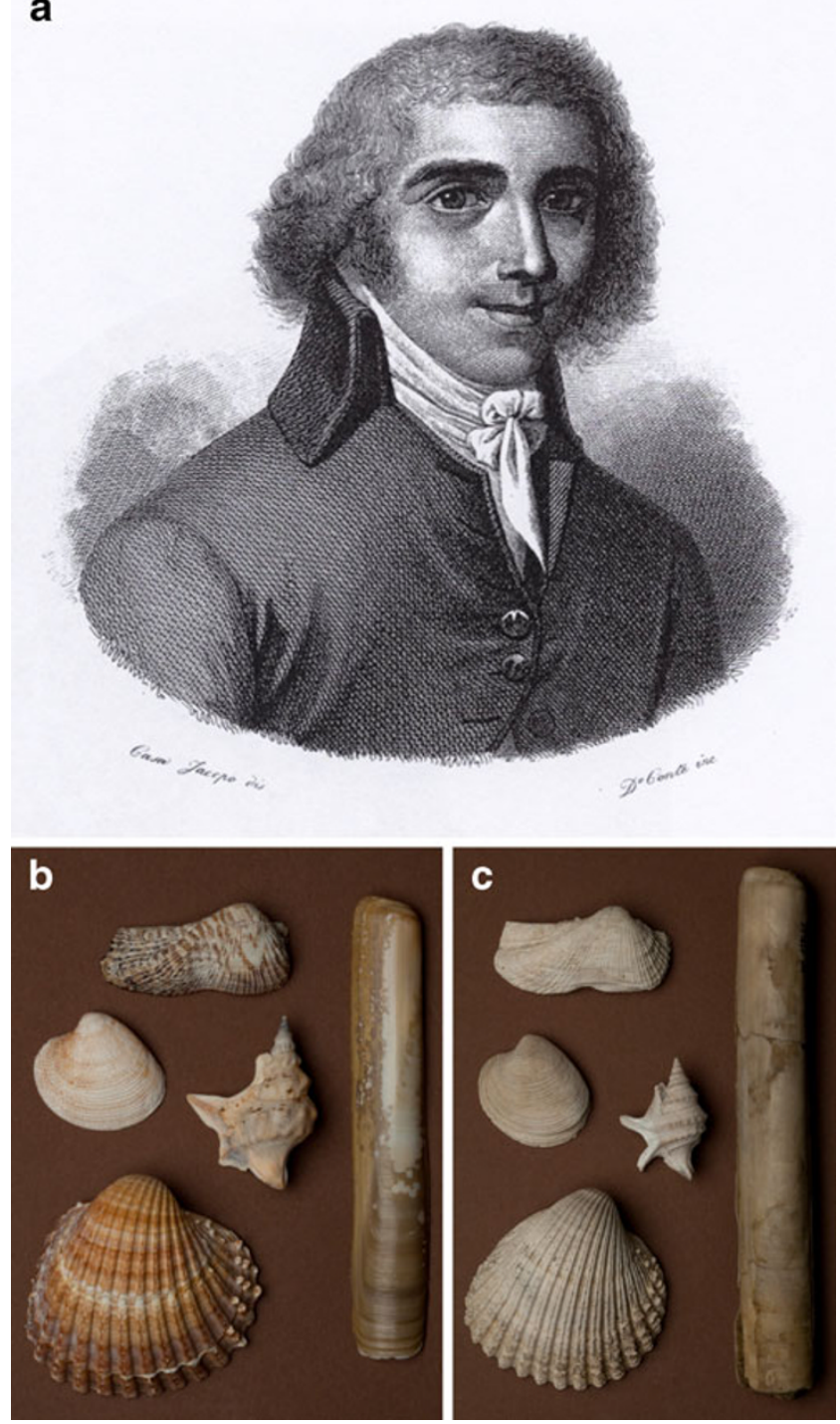

Fig. 1 Giambattista Brocchi and the comparison of living and fossil Mediterranean mollusks. a Portrait of Giambattista Brocchi (17721826) as a young man. b Five common Mediterranean living mollusk species. c The same species as found within Tertiary strata in Italian regions visited by Brocchi
Brocchi's text] and the study of modern molluscan systematics without comparison with their fossilized antecedents, writing:

I agree that wanting to describe all the shells of the sea, to sort them by order, genera and species does not lead to great consequences, but if no one dared to treat in an academic way marine conchology, how could we usefully study fossil conchology which gives units of measure in geology and paves the way to so many beautiful speculations?

To Brocchi, in other words, the comparison of living species with their fossil analogs was what leant meaning ("beautiful speculations") to the entire enterprise of tracing examples of "..distinct genealogy...of descent."

Brocchi's best-known "beautiful speculation" was the analogy between the births and deaths of individuals and the births and deaths of species. This "Brocchi's analogy" (Pancaldi 1983) was framed in purely naturalistic, secondary causal terms (Rudwick 2005, 2008; Eldredge 2009a, b). There are natural causes underlying the births and deaths of individuals (i.e., implicitly sidestepping the issue of however much the Deity might ultimately be responsible for the births and deaths of individual humans). And, likewise, there are natural causes for the births and deaths of species.

If Brocchi did not speculate on the natural causes of the births of species, he did however push his analogy with the historical fates of individuals further by asserting that species of different taxa characteristically have different life spans-just as individuals of different taxa have different longevities. He writes: "I thought I had enough inductions to venture to say that it is an established law that species die like individuals, and that they are bound to make their appearance in the world for a fixed span of time." Thus, just as mayflies live much shorter lives than deer, likewise mammalian species typically have shorter geological life spans than mollusks. For Brocchi, the life spans of individual species are as built-in as are the life spans of individuals. Nature, of course, can cut short these life spans prematurely.

Brocchi saw species, like individuals, as discrete entities - with births, life spans, and deaths. But he also saw species as stable entities, as the aging process leading to species deaths produces only subtle changes in such features as reproductive vitality: [the changes] "that take place in the animal machine and that are the symptoms of decline of the species, do not produce a large change in structure, what would be a true metamorphosis." So much for M. Lamarck!

Brocchi links his vision of genealogical descent through the gradual births and deaths of species to the moderniza- 
tion of faunas through time. In a passage disputing Cuvier's vision of catastrophes as the root cause of species extinction, Brocchi says "it does not account for the loss of fresh water shells and, what is more important, it cannot be applied to the loss of terrestrial quadrupeds, a matter on which he [i.e. Cuvier] has himself observed that all unknown species belong to the rocks older than those others that bear remains of known species or more similar to living ones." Much later, Cuvier, in his eulogy of Lamarck (Jameson 1836, English translation) pronounced the modernization of faunas in progressively younger rocks as "the deepest, perhaps, of all the mysteries which inanimate nature presents to our view"-likely the forerunner to Herschel's (1836-written one month after Jameson's translation of Cuvier's eulogy appeared) remark on the "mystery of mysteries" to Lyell, subsequently quoted in the second sentence of the Origin of Species (Darwin 1859).

In and of themselves, Brocchi's "beautiful speculations" surrounding the origin of the modern Italian molluscan fauna are of great interest. As Rudwick has put it, Brocchi's analogy "...respected the reality of species as discrete entities or natural kinds, rather then dissolving them in an endless flux of transmutation. It also suggested, though less explicitly, that the origin of species, might have an equally natural, yet episodic, mechanism, analogous to the birth of individuals (Rudwick 2005)." Exactly so. Brocchi's was a distinct form of transmutation. That Brocchian transmutation can be shown to have directly been the basis of Darwin's initial empirical testing of transmutation - and his own earliest transmutational speculations - puts the work of this great Italian paleontologist at the very heart of the beginnings of modern evolutionary thought.

\section{Brocchi's Fame in Britain}

How did Darwin become aware of Brocchi's ideas? Though there is a modest paper trail of Brocchian transmutation published in English in the years 18161830 , only two such references are definitely known to have been read by Charles Darwin. Yet it is almost certain that he would have been exposed to some of the others, especially as a medical student in Edinburgh in 1825-26, when he was an acolyte of the Lamarckian Robert Grant and a student of the like-minded Robert Jameson (Browne 1995; Eldredge 2009a).

Of the British publications containing elements of Brocchian transmutation, only two mention Brocchi by name. In 1816, geologist Leonard Horner wrote a 24page review of Brocchi's (1814) monograph for the Edinburgh Review (Horner 1816). Horner says at the outset that, though "we should have been glad to have had, in this Introduction, the descriptions and the author's reasonings upon them, less mixed up together: it would have rendered both more intelligible to the reader..."; he hastens to add that "we are by no means of the opinion, that the geologist ought to confine himself to a bare narration of the facts, and that he ought to refrain from all theoretical speculations upon them." Showing his fluency in Italian, he then translates Brocchi directly on the subject of importance of theoretical "systems" in geological science.

Nonetheless, Horner decides to "confine ourselves principally to the matters of fact" and not examine "the author's theoretical opinions." Good to his word, Horner's review is essentially an overview of Italian geology, through Brocchi's eyes and those of others, including his own. Only at the end of the review does Horner speak of the differences between Lamarck's Paris Basin mollusks and those described by Brocchi-in terms of the relative numbers in each fauna that can be confidently assigned to still-living species. That-plus a lucid statement praising Brocchi for his discussion on the difficulties - and importance of-identifying the relatives of fossil species with those modern species living locally, vs. in far-flung regions, is all Horner has to say about Brocchi's "beautiful speculations."

Of crucial importance, the first geology teacher of the young Charles Lyell, William Buckland, helped Horner in bringing Brocchi to the attention of a broad circle of British geologists (Rudwick 2005) — sufficiently so that in 1827 a brief notice of Brocchi's death appears in the same volume of Jameson's New Edinburgh Philosophical Journal as the second of the two Brocchian-flavored anonymous essays discussed below (Anonymous 1827a).

Significantly, the only discussion of Brocchi's analogy that actually cites him by name came in 1832, in volume 2 of Lyell's Principles of Geology (Eldredge 2009a). Lyell had by that time become Horner's son-in-law, had traveled extensively in Italy, and is said, like his father-in-law, to have been fluent in the language. Brocchi's numerical analysis of the percentage of his fossil species with living representatives (more in Italy than in Lamarck's data on the Paris Basin) was a clear forerunner of Lyell's use of such percentages in the relative dating of Tertiary sedimentsdeveloped especially in volume 3 of his Principles (Rudwick 2008). But it was Lyell's concise description of Brocchi's analogy in volume 2 that would have caught Darwin's eye at least as much. Darwin received Lyell's volume 2 in late November 1832 in Montevideo, Uruguay (Eldredge 2009a).

But elements of Brocchi's ideas appeared before that, including Robert Jameson's (1827) fifth edition of his translation of Cuvier's Theory of the Earth (a portion of Cuvier 1812) and two anonymous essays published in 
Jameson's New Edinburgh Philosophical Journal in 1826 and 1827 (Anonymous 1826, 1827b). In Jameson's (1827, p. 431) chapter on On the Universal Deluge, he writes:

And, like the formation of rocks, we observe a regular succession of organic formations, the later always descending from the earlier, down to the present inhabitants of the earth, and to the last created being who was to exercise dominion over them.

Thus, Jameson has phylogenetic descent, the modernization of the fauna - and even the evolution of humans wrapped neatly up in a single sentence. Jameson's book concludes with a set of tables charting the distribution of genera known only from the Recent, those known from both the modern fauna and as fossils, and those only found as fossils - clearly shades of Brocchi and Lamarck.

Fraught with transmutational concepts (Eldredge 2009a), the two anonymous essays were most likely written by two different authors - as the earlier one, with its favorable emphasis on Lamarck, vestiges of Neptunian geological thinking, and the phrase "origin of the animal species" (title of at least one lecture in Jameson's natural history course that Darwin was enrolled in) suggest that the author was indeed the journal's editor, Robert Jameson (Secord 1991).

Despite its emphasis on Lamarck, however, the anonymous essay of 1826 makes it clear that species, like individuals, may well have built-in longevities - and the analogy between individuals and species is clear. Extinction is a threefold phenomenon to this author: species may only seem extinct, but in fact survive in regions not yet explored; or they may, in pure Lamarckian fashion, slowly transform themselves into a descendant species - in which case, species are far from discrete and stable; or they might simply fade away and die of old age (Anonymous 1826). No mention here of the external environmentally driven forces of extinction soon to be championed by Lyell in his Principles - and acknowledged as a possibility by Brocchi (1814).

The second anonymous essay introduces the more precise imagery of replacement of extinct species by other, descendant species. In this and other succeeding references, the terms/phrases "replacement" or "takes the place of" are always explicit in what would today be called a "phylogenetic" context - rather than in the sense of (not necessarily related) "vicars" performing analogous roles in geographically disjunct ecosystems. The author wrote, for example (Anonymous 1827 b, p. 298), "New animals and vegetables have assumed the place of those that have been destroyed, and whose ancient existence is only revealed to us by their fossil remains." And again,

Certain primitive types have indeed completely disappeared, but they are found existing at various epochs, and their remains are blended with those of more modern types; along with new species of types still existing, we find some of anterior epochs; certain genera that yet obtain are common to all the terms of the series; and toward the end of the series, we find the remains of some of our present species along with ancient types and extinct species.

Yet it is the writings of John Herschel which matter most in the search for definite links between Darwin and Brocchian transmutation. In his autobiography (Barlow 1958), Darwin writes that, along with Humboldt's Narrative, Herschel's Introduction (sic) to the Study of Natural Philosophy, first published in 1830 (Herschel 1987), were the two books that he read at Cambridge that "stirred up in me a burning zeal to add even the most humble contribution to the noble structure of Natural Science."

Science ("natural philosophy") in Great Britain by the 1820 s and 1830 s was imbued with the spirit that natural phenomena have natural causes - and that it is the central task of science to describe both natural objects and specify the interactions among them. "Nature offers us two sorts of subjects of external contemplation of the natural worldobjects and their mutual actions," as Herschel (1830) put it. Brocchi, too, had made it clear that he was looking for natural causal explanations (e.g., "match with physics"see the translation in Dominici 2010, in this issue). In Great Britain, no one epitomized that spirit more than John Herschel himself, whose entire work was dedicated to what has later been called the "logic of scientific discovery." Summarizing what was then known of the natural world, Herschel made it clear throughout that, however the Deity might be invoked as a Final Cause, there are always secondary, natural causes to be found to account for natural phenomena - and that it is the natural philosopher's task to discover them.

Including transmutation, Herschel (1830) wrote on fossils:

These remains are occasionally brought to light; and their examination has afforded indubitable evidence of the former existence of a state of animated nature widely different from what now obtains on the globe, and of a period anterior to that in which it has been the habitation of man, or rather, indeed, of a series of periods, of unknown duration, in which both land and sea teemed with forms of animal and vegetable life, which have successively disappeared and given place to others, and these again to new races approximating gradually more and more nearly to those which now inhabit them, and at length comprehending species which have their counterparts existing.

Herschel wrote these lines in a book devoted to the advocacy of the search for natural causal explanations of 
natural phenomena. It is essentially what Brocchi and the authors of the two anonymous essays had already said - in if anything a more prominent place. If Darwin had somehow managed not to learn of Brocchi's ideas from his mentors-Grant and Jameson in Edinburgh, and perhaps from even the intellectually curious Henslow at Cambridge (Kohn 2005) — he could hardly have missed these words in Herschel (1987).

More famous, of course, are those lines Herschel (1836) penned in 1836 in a letter to Lyell "Of course I allude to that mystery of mysteries, the replacement of extinct species by others." Replacement of extinct species by others, once again. By that time, though, and by the time Darwin and Herschel met in South Africa (Warner 2009), Darwin (1835a) had long since written his essay on February 1835, replete with Brocchi's analogy and his own thoughts on the births and deaths of species.

\section{Darwin as Brocchian Transmutationist: 1832-1837}

From his very first stop in Cap de Verde Islands (January 1832) (Eldredge 2009a) and whenever subsequent opportunities allowed, Darwin was comparing fossils he collected with the living members of the Recent biota. Fortunate that the fossiliferous sediments he saw in the first year of his trip were geologically young, he concluded that either (1) the fossil and living species were identical (marine invertebrates on Quail Island, Cap de Verde, as well as those preserved at Punta Alta, Bahia Blanca, Argentinaobserved and collected in September-October, 1832); or (2) the fossils were extinct members of higher taxa with remote (non-congeneric) living representatives belonging to the same higher taxon [as with the giant ground sloths and glyptodonts at Bahia Blanca-members of the "Edentata" (now Xenarthra)]; or (3) as in his one critical intermediate case, the fossils were of an extinct species closely related to ("congeneric with") a species in the modern fauna: Darwin's "cavy" (which he sometimes called an "agouti") collected at Monte Hermoso (Bahia Blanca), which he thought to be an extinct species smaller ("lesser") than the extant Patagonian cavy (Eldredge 2009a; Brinkman 2009).

Like Brocchi (and the 1826 anonymous essayAnonymous 1826), Darwin was especially focused on taxa that were endemic to their locales: the cavies and edentates, for example, are endemic to the Americaswith the preponderance of their occurrences in South America. This can be read, clearly, as an attempt to control for migration in the search for the explanation of the appearance of new species (Eldredge 2009a).

The cavy example figures sporadically in Darwin's (1832a) geological notes (especially for Bahia Blanca), in two letters to Henslow (Darwin 1832b, 1834), and again in his essay, "February 1835" (Darwin 1835a). Like Brocchi before him, Darwin seems to have preferred to focus on extinction rather than on the births of species - the former simply being a more acceptable topic of discussion than the latter. But consider Darwin's use of extinction as a smokescreen for the births of species, as he writes (Darwin 1832a):

I could perceive traces of 4 or 5 distinct animals: two of which certainly belonged to the Rodentia. One must have been allied to the Agouti; the tarsi \& Metatarsi belong to an animal less than the present common inhabitant, Cavia patagonica.

(b) The Agoutis are all proper to S. America; \& none have hitherto been found in a fossil state:-To conclude with the organic remains I have shown that some of the bones probably belong to the Edentata. \& that the osseous plates are supposed to belong to the Megatherium.

It is footnote (b) that reveals why Darwin thinks the cavy is so important:

(b) "It is interesting to observe that this tribe of animals [the Agoutis-inserted], which is now peculiar to S. America, should in this epoch when the Megatherium flourished, also be present-showing that with the extinction of one genus, that of others did not follow."

Though Darwin was indeed interested in showing that extinction was not catastrophic but rather took different elements of a fauna at different times, the clear implication is that, while taxa such as the genus Megatherium became extinct, the fossil cavy species, now also extinct, has been replaced by a closely related, congeneric species. Thus Darwin was looking at the replacement of extinct by modern congeneric species before he received Lyell's volume 2 in late November 1832 (Fig. 2).

In his two letters to Henslow (Darwin 1832b, 1834), Darwin obsesses about keeping the labels together with his specimens already shipped home - as he is concerned to show that the fossil cavy is indeed of the same age as Megatherium. When he returned to Bahia Blanca in 1833, Darwin wrote in his notes of his worries that the rocks of Punta Alta and Monte Hermoso are not in fact of the same age (and, in fact, they are not), but as the trip wore on, he forgot his anxieties and treated them as though they in fact were at least roughly of the same age.

As the voyage progressed, Darwin applied his replacement thinking to living species (Eldredge 2009a). His Zoology Notes (Keynes 2000) have many examples (mainly of the avifauna-funariids and of course the famous rhea example) where Darwin says one species takes the place of another congeneric species-not so much ecologically as 
Fig. 2 Comparison of fossil and living biota at Bahia Blanca as seen by Charles Darwin early in 1832. a The extinct Edentate megafauna (including such elements as glyptodonts and giant ground sloths) is today represented by distantly allied armadillos and sloth species. On the other hand, one of the small fossil "Rodentia" seemed to Darwin to be an extinct species congeneric with the living "Agouti" (Patagonian cavy). By merging fossil mammals from two different localities and interpreting them as coeval, Darwin was showing that some mammalian genera faced extinction where others did not. In further contrast, the species-level identity of South American fossil and living mollusks at Bahia Blanca showed persistence of invertebrate species throughout the entire interval - a pattern Darwin had first observed at Santiago in the Cap de Verde Islands. b The fossil caviomorph rodent as depicted in the Zoology of the Voyage of the Beagle in 1840 , interpreted by Darwin as an extinct species directly related to the living cavy. c The living Patagonian cavy ("mara")
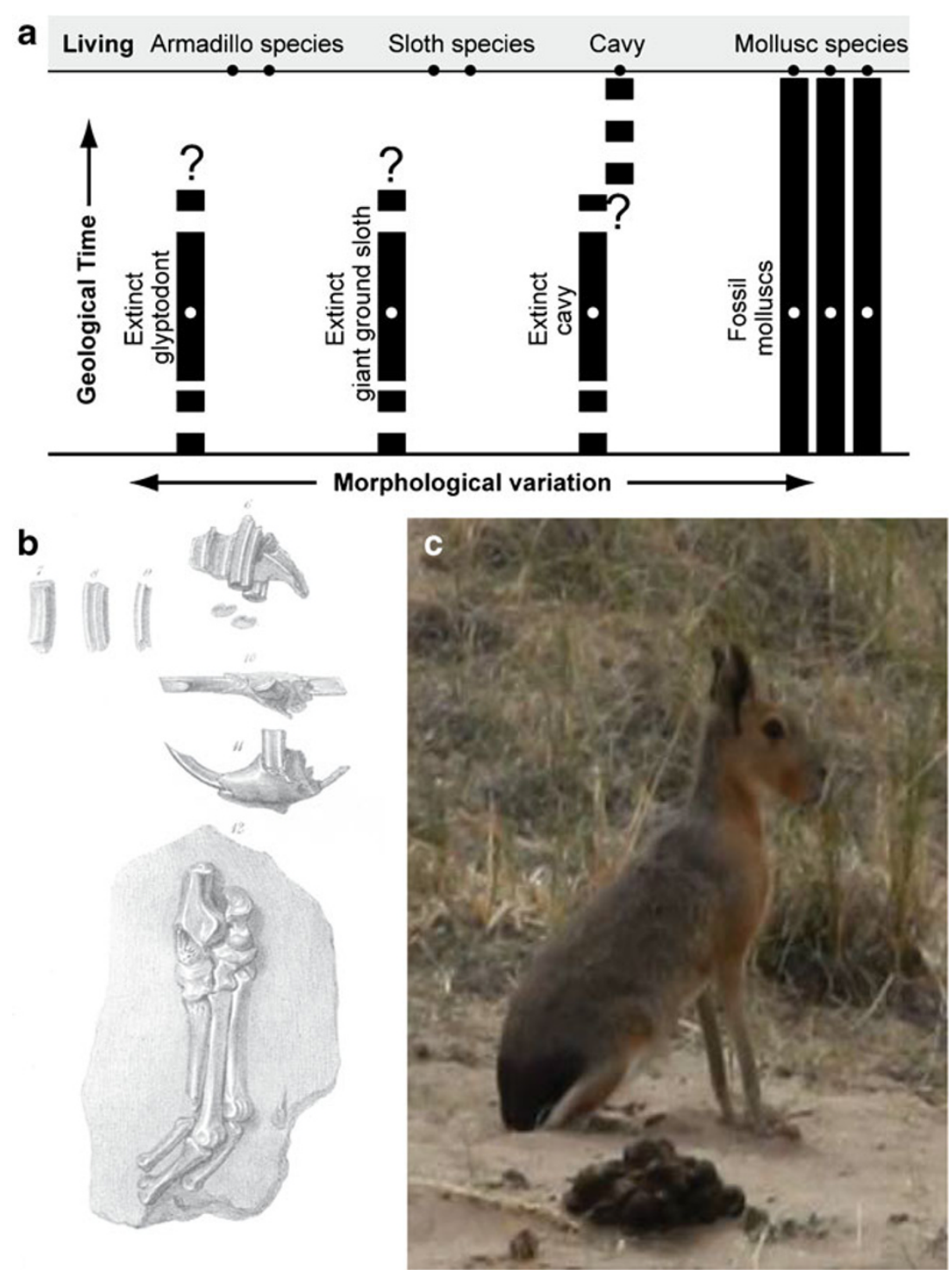

geographically. With the rheas, Darwin makes it clear that the two do not intergrade where their ranges overlap slightly along the Rio Negro (the traditional divide between the Pampas to the north and Patagonia to the south).

When he applies his geographic replacement thinking to offshore islands for the first time, he observes that the Falkland Fox is an "individual" species ("...proof of its individuality as a species") (Keynes 2000, p. 209) and that the populations on East and West Falklands show consistent differences from one another. His line of geographic thinking reaches its apogee, of course, in the Galapagos-where he sees that the mockingbirds are closely allied with the Thenca of Chile (and the Callandria species of Argentina) but that, as well, the mockingbird species (or varieties) on some of the separate islands (the older ones in the southeastern portion of the Archipelago) are consistently different from one another. No matter how similar two geographically disjunct species may be, they are to the young Darwin always discrete. No Lamarckian blend of characters is to be found in the young Darwin's data and observations on the Beagle - no matter how much he may have modified his views by the time he wrote the Origin.

It is in his brief essay on February 1835, probably written in Valdivia, Chile, where Darwin first writes explicitly about the births as well as the deaths of species - and, in openly disagreeing with Lyell and siding with Brocchi (though not mentioning him by name), entertaining the notion that species do have internally prescribed life spans (Darwin could see no geological evidence for environmental change accounting for 
the extinctions of his fossil taxa-Darwin 1835a). He continues:

If the existence of species is allowed, each according to its kind, we must suppose deaths to follow at different epochs, \& then successive births must repeople the globe or the number of its inhabitants has Varied exceedingly at different periods.-A supposition in contradiction to the fitness, which the Author of Nature has now established.

In other words, births of new, replacement species must follow soon after deaths of their older congenerics - or else there would be fluctuations in species diversity that seems to be the norm (attributing this to God, but in reality lifting the idea from Lyell that species diversity is more or less always steady-state).

Darwin's well-known, explicitly transmutational passages, in the second part of the Red Notebook (Darwin 1836-1837a; Herbert 1987), are basically a re-write of February 1835. Brocchi's analogy between individuals and species, with their respective births and deaths, is therealong with the supposition that species have internally regulated longevities.

There, too, Darwin equates the patterns of replacement in time (substituting the supposed fossil camel Macrauchenia as antecedent to the living guanaco-for the original cavy example) with the patterns of geographic replacement of the two rhea species. Species are discrete, and arise "per saltum" from their ancestors. Darwin's knack of interpreting vertical geological succession in terms of geographic landscapes and depositional processes [made clear in a passage in yet another letter to Henslow (Darwin 1835b) interpreting lavas interbedded with Mesozoic sediments—see Eldredge 2009c] may well be at play with his equation of geographic with stratigraphic replacement patterns of closely related species. That he was on the verge of developing a geographically based theory of species births is confirmed in the opening pages of his Notebook B (written between 1836 and 1837, see Kohn 1987 for transcriptions) - where the analogy between births and deaths of individuals and species is again prominent-along with the explicit idea that new species arise in geographic isolation.

But here is the clincher: In 1844, Darwin wrote Leonard Jenyns (brother-in-law of Darwin's Cambridge mentor J. S. Henslow-and, like Henslow, a prior nominee for the position Darwin ended up taking on the Beagle). Here the connection between Darwin and Brocchi is explicit and undeniable:

With respect to my far-distant work on species, I must have expressed myself with singular inaccuracy, if I led you to suppose that I meant to say that my conclusions were inevitable. They have become so, after years of weighing puzzles, to myself alone; but in my wildest day-dream, I never expect more than to be able to show that there are two sides to the question of the immutability of species, i.e. whether species are directly created, or by intermediate laws, (as with the life \& death of individuals). I did not approach the subject on the side of the difficulty in determining what are species \& what are varieties, but (though, why I sh ${ }^{\mathrm{d}}$ give you such a history of my doings, it $\mathrm{w}^{\mathrm{d}}$ be hard to say) from such facts, as the relationship between the living \& extinct mammifers in S. America, \& between those living on the continent \& on adjoining islands, such as the Galapagos-It occurred to me, that a collection of all such analogous facts would throw light either for or against the view of related species, being codescendants from a common stock (Darwin 1844).

Darwin says he was weighing the possibility that species are created through "intermediate" laws - "as with the life and death of individuals." Imbued with the scientific Zeitgeist of his times, by his own account, Darwin was a Brocchian transmutationist - quite obviously so from his earliest experiences on the Beagle.

Acknowledgments We thank colleagues Gilbert Klapper and Harold B. Rollins for comments on earlier drafts of this manuscript. Stuart Wallace helped search for connections between the work of Brocchi and contemporary Edinburgh geologists. In Bahia Blanca, Paul Brinkman, Teresa Manera, and Rodrigo Tomassini provided stimulating conversation on various aspects of Darwin, paleontology, and transmutation.

\section{References}

Anonymous. Observations on the nature and importance of geology. Edinb New Philos J. 1826;1:293-302.

Anonymous. Death of Professor Brocchi. Edinb New Philos J. $1827 \mathrm{a} ; 3: 383$.

Anonymous. Of the changes which life has experienced on the globe. Edinb New Philos J. 1827b;3:298-301.

Barlow N. The autobiography of Charles Darwin, 1809-1882. London: John Murray; 1958.

Brinkman P. Charles Darwin's Beagle voyage, fossil vertebrate succession, and "the gradual birth \& death of species". J Hist Biol. 2009;43:363-99. doi:10.1007/s10739-009-9189-9.

Brocchi GB. Conchologia fossile subapennina con osservazioni geologiche sugli Apennini e sul suolo adiacente. Milan: Stamperia Reale; 1814.

Browne J. Charles Darwin. Voyaging. Princeton: Princeton University Press; 1995.

Cuvier G. Recherches sur les ossemens fossiles. Paris: Deterville; 1812. 4 vols.

Darwin C. On the origin of species by means of natural selection, or the preservation of favoured races in the struggle for life. London: John Murray; 1859. 
Darwin C. Darwin Archive Dar 42+97-102.Cambridge University Library; 1835 a

Darwin C. Geological notes. Darwin Archive, DAR 32.1: 34 St. Jago: 20; Bahia Blanca DAR 32.1: 62 ff. Cambridge University Library; 1832a.

Darwin C. Notebook B. Down House, UK. 1837. Kohn D. Notebook B. In: Barrett PH et al., editors. Charles Darwin's notebooks. Ithaca: Cornell University Press; 1987. p. 1836-44.

Darwin C. Red Notebook. Down House, UK. See Herbert S 1987 for transcription. 1836-1837a.

Darwin C. Letter to Henslow JS. 12 Aug 1835. Letter 283. Darwin correspondence project. Cambridge University Library. 1835b.

Darwin C. Letter to Henslow JS. 24 Nov 1832. Letter 192. Darwin correspondence project. Cambridge University Library. 1832b.

Darwin C. Letter to Henslow JS. Mar. Letter 238. Darwin correspondence project Cambridge University Library. 1834.

Darwin C. Letter to Jenyns L. 25 Nov 1844. Letter 793. Darwin Correspondence Project. Cambridge University Library. 1844.

Dominici S. Brocchi's subapennine fossil conchology. Evo Edu Outreach 2010; this issue.

Eldredge N. Experimenting with transmutation: Darwin, the Beagle and evolution. Evo Edu Outreach. 2009a;2:35-54.

Eldredge N. A matter of individuality. Evo Edu Outreach. $2009 \mathrm{~b} ; 2: 150-5$.

Eldredge N. Keeping in touch. Review of Charles Darwin. The beagle letters. Evolution. 2009c;63:2481-5.

Eldredge, N. Editor's Corner: How systematics became "phylogenetic." Evo Edu Outreach 2010; this issue.

Elliot H. Zoological philosophy by J.B. Lamarck. Chicago: University Chicago Press; 1984. translation.

Herbert S. Red notebook. In: Barrett PH et al., editors. Charles Darwin's notebooks 1836-1844. Ithaca: Cornell University Press; 1987. p. 17-81.

Herschel JFW. A preliminary discourse on the study of natural philosophy. Chicago: University of Chicago Press; 1830. 1987.

Herschel JFW. Letter to C. Lyell, 20 February 1836. Quoted in W. H. Cannon, The Impact of Uniformitarianism. Two letters from John Herschel to Charles Lyell, 1836-39. Proc Am Philos Soc. 1961;105:301-14.
Horner LLG. Conchiologia fossile subapennina. Edinb Rev. 1816;26:156.

Hull DL. Darwin and his critics. Chicago: Univ. Chicago Press; 1973.

Jameson R. Essay on the Theory of the Earth by Baron G. Cuvier. With Geological Illustrations, by Professor Jameson. William Blackwood, Edinburgh; and T. Cadell, Strand, London; 1827.

Jameson R. Eulogy of Lamarck by Baron G. Cuvier. Edinb New Philos J. 1836;20:1-22.

Keynes RH, editor. Charles Darwin's zoology notes and specimen lists from H. M. S. Beagle. Cambridge: Cambridge University Library; 2000

Kohn D. Notebook B. In: Barrett PH et al., editors. Charles Darwin's notebooks. Ithaca: Cornell University Press; 1987. p. 1836-44.

Kohn D et al. What Henslow taught Darwin. Nature. 2005;436:643-5.

Lamarck J-B. Mémoires sur les fossiles des environs de Paris, comprenant la étermination des espèces qui appartiennent aux animaux marins sans vertèbres, et dont la plupart sont difurés dans la collection des vélins du Muséum. Ann Mus Hist Nat. 1802-1809;1-14:299-312, and many further brief installments.

Lamarck J-B. Philosophie Zoologique. Paris: Dentu; 1809.

Lyell C. Principles of geology, vol. 2. London: John Murray; 1832. Citations in Secord JA (ed) Charles Lyell. Principles of geology. London and New York: Penguin Books.

Pancaldi G. Darwin in Italia. Il Mulino, 1963. Updated and expanded edition, Darwin in Italy. Bloomington: Indiana University Press; 1983. 1991.

Rudwick MJS. Bursting the limits of time. Chicago: University of Chicago Press; 2005.

Rudwick MJS. Worlds before Adam. Chicago: University of Chicago Press; 2008.

Secord JA. Edinburgh Lamarckians: Robert Jameson and Robert E. Grant. J Hist Biol. 1991;24:1-18.

Warner B. Charles Darwin and John Herschel. S Afr J Sci. 2009;105:432-9.

Whewell W. History of the inductive sciences. New York: Appleton; 1858.

Whewell W. History of the inductive sciences. London: Parker; 1837. 